\title{
Hubungan Antara Kepuasan Kerja Dengan Kinerja Perawat Dalam Ketepatan Pemberi- an Obat Di Ruang Rawat Inap RS Baptis Batu
}

\author{
Yohanna Maria Magdalena Rumahorbo ${ }^{1}$, Susilaningsih², Risna Yekti Mumpuni³
}

1,2,3 Program Studi Ilmu Keperawatan, Sekolah Tinggi Ilmu Kesehatan Maharani Malang, Indonesia

\section{INFORMASI ABSTRACT}

Korespondensi:

yohanamaria1985@gmail. com

Keywords:

Job Satisfaction, Nurse Performance, Drug Accuracy
The purpose of this study is know whether there is a correlation between nurses' job satisfaction and the accuracy of drug administration in the inpatient room at the Baptist Hospital in Batu.

This type of research is a correlational research design used is cross sectional design. The populations in this study were all inpatient nurses who fit the inclusion criteria as many as 32 nurses. The sampling technique used is total sampling techniques and data collection is done through a questionnaire and checklist by using the Lamda test data analysis method.

The results of the Lamda test have a probability (sig) of 0.033 . As the probability value is $<0.05$, the interpretation of the results $H o$ is rejected and $H 1$ is accepted.

So it can be concluded that there is a correlation between nurse job satisfaction and the accuracy of drug administration in the inpatient room at the Baptist Hospital in Batu. The suggestions of this research is that it is expected that hospitals can improve the welfare of employees so that the quality of nurses' performance can be obtained for the advancement of service to patients. 


\section{PENDAHULUAN}

Pemberian obat merupakan salah satu prosedur tindakan keperawatan yang paling sering dilakukan oleh perawat. Dalam tindakan pemberian obat ketelitian sangat penting dilakukan agar efek obat menjadi maksimal. Berbagai komplikasi termsuk kematian dapat terjadi bila obat diberikan dalam dosis yang tidak tepat, teknis pemberian yang salah dan identifikasi yang tidak cermat (Smith, 2010). Kesalahan dalam pemberian obat tersebut dapat berupa pemberian obat yang salah, resep yang tidak akurat memberikan obat melalui jalur yang tidak tepat dan waktu pemberian yang tidak tepat, serta pemberian dosis yang salah..Dari hasil penelitian lain yang dilakukan oleh Yunie Armiyat (2007) yang dikutip oleh Dahlia dkk (2015) dengan penerapan prinsip enam benar dalam pemberian obat diruang rawat inap RS Dr. Kariadi Semarang menunjukkan bahwa perawat belum menerapkan prinsip enam tepat dalam pemberian obat secara keseluruhan, ada $81.4 \%$ perawat sudah melakukan tepat dosis, $70 \%$ perawat sudah melakukan tepat waktu, $5.7 \%$ perawat tidak memanggil nama pasien saat memberi obat, $98.9 \%$ perawat belum menerapkan prinsip tepat cara, $10 \%$ perawat tidak tepat dokumentasi, dan yang terakhir yang perlu diperhatikan bahwa $100 \%$ perawat tidak tepat obat.

Dari hasil studi pendahuluan di RS Baptis Batu didapatkan pada bulan Januari 2016 - Juni 2017, terdapat insiden yang berhubungan dengan ketidaktepatan pelayanan pengobatan oleh perawat rata - rata 6-7 kasus setiap bulannya antara lain adalah kesalahan mengerjakan advis, kesalahan penulisan dosis, kesalahan masuk box pasien lain, serta obat yang tidak diberikan kepada pasien. Berdasarkan hasil investigasi tim KKPRS penyebab ketidaktepatan pelayanan obat ini terbanyak dikarenakan ketidaktelitian oleh perawat, terburuburu, tidak melakukan double cek, dan belum ada SPO yang baku tentang cara pembuatan kartu obat. menurut WHO (2009) faktor-faktor yang dapat mempengaruhi ketepatan pemberian obat yaitu faktor organisasi, faktor manajemen unit, dan faktor individu. Ketiga faktor tersebut mempengaruhi perilaku perawat dalam pemberian obat dan pada akhirnya akan memberikan dampak pada outcomes keselamatan pasien. Keberhasilan pelayanan keperawatan sangat ditentukan oleh kinerja para perawat itu sendiri Oleh karena itu, peningkatan kinerja perawat perlu dan harus selalu dilaksanakan melalui sistem yang terstandar sehingga hasilnya lebih optimal (Kuntjoro, 2015). Menurut Nursalam (2016) yang mengutip pendapat Gibson, ada tiga faktor yang berpengaruh terhadap kinerja yaitu: (1) faktor individu meliputi kemampuan, keterampilan, latar belakang keluarga, pengalaman kerja, tingkat sosial, dan demografi seseorang, (2) faktor psikologis meliputi persepsi, peran, sikap, kepribadian, motivasi, dan kepuasan kerja, (3) faktor organisasi meliputi struktur organisasi, desain pekerjaan, kepemimpinan, sistem penghargaan. Hal inilah yang menjadi latar belakang peneliti untuk melakukan penelitian dengan judul Hubungan Antara Kepuasan Kerja Perawat Dengan Ketepatan Pemberian Obat di Ruang Rawat Inap RS.Baptis Batu”.

\section{METODE PENELITIAN}

Jenis penelitian ini adalah rancangan penelitian correlational.dengan menggunakan desain cross sectional. Populasi dalam penelitian ini adalah seluruh perawat diruang rawat inap RS. Baptis Batu yang sesuai dengan kriteria inklusi berjumlah 32 org. Sebelum penelitian dilakukan terlebih dahulu mengajukan permohonan izin kepada intitusi untuk mendapatkan persetujuan. Setelah mendapatkan persetujuan, kemudian peneliti melakukan wawancara dan memberikan formolir kepada responden dengan menekankan pada masalah etika meliputi Informed Consent, Anonymity, Confidentiality, Kemandirian, Kejujuran. Tekhnik pengambilan sampel yang dilakukan pada penelitian ini adalah dengan tekhnik total sampling, yaitu sejumlah 32 responden yang sesuai dengan kriteria inklusi. Variabel dalam penelitian ini adalah variabel independen yaitu kepuasan kerja perawat dan variabel dependen yaitu ketepatan pemberian obat. Instrumen penelitian yang digunakan pada penelitian ini adalah kuesioner yang berisi pertanyaan tentang kepuasan kerja perawat yang berjumlah 20 pertanyaan dan cek list untuk ketepatan pemberian obat menggunakan 7 benar sejumlah 13 pernyataan. Pada penelitian ini tidak dilakukan uji validitas dan reabilitas karena kuesioner kepuasan kerja perawat dan cek list pemberian obat bersumber pada buku yaitu buku Metodologi Penelitian Ilmu Keperawatan edisi 4 dan Fundamental Nursing. Data yang diperoleh dianalisa dengan analisa univariat dan analisa bivariate. Analisa univariat dilakukan dengan persentase tiap variable dan analisa bivariate didapatkan dari data yang dikumpulkan kemudian diuji dengan uji Lamda 
HASIL

Tabel 1. Karakteristik responden

\begin{tabular}{lcc}
\hline \multicolumn{1}{c}{ Kategori } & Frekuensi & $\%$ \\
\hline Usia & & \\
$24-30$ & 19 & $59,37 \%$ \\
$31-35$ & 7 & $25 \%$ \\
$36-40$ & 4 & $12,5 \%$ \\
$41-45$ & 1 & $3,12 \%$ \\
\hline Masa Kerja & & \\
$3-5$ & 15 & $46,87 \%$ \\
$6-10$ & 11 & $37,5 \%$ \\
$11-15$ & 0 & $0 \%$ \\
$16-20$ & 5 & $15.62 \%$ \\
\hline Status Perkawinan & & \\
Kawin & 24 & $75 \%$ \\
Belum kawin & 8 & $25 \%$ \\
\hline Pada tabl dias &
\end{tabular}

Pada tabel 1 diatas dapat dilihat bahwa usia terbanyak dari responden adalah 24-30 tahun sebanyak $59,37 \%$, untuk masa kerja yang terbanyak yaitu 3-5 th sebanyak $46,87 \%$ dan status perkawinan paling banyak 75\% yaitu kawin.

Tabel 2. Kategori Kepuasan Kerja Perawat

\begin{tabular}{lcc}
\hline Kategori & Frekuensi & Persentase (\%) \\
\hline Sangat tidak puas & 0 & 0 \\
\hline Tidak puas & 4 & $12,5 \%$ \\
\hline Cukup puas & 15 & $46,875 \%$ \\
\hline Puas & 11 & $34,375 \%$ \\
\hline Sangat puas & 2 & $6,5 \%$ \\
\hline
\end{tabular}

Berdasarkan tabel 2 diatas menunjukkan bahwa untuk variabel kepuasan kerja perawat terbanyak menyatakan cukup puas sebanyak 15 responden $(46,875 \%)$ dan menyatakan sangat puas sebanyak 2 responden $(6,5 \%)$.

Berdasarkan tabel 3 diatas menujukkan dimensi gaji yang memiliki responden paling mencolok yaitu $6,875 \%$ menyatakan tidak puas dan $43,75 \%$ menyatakan cukup puas dalam hal sistem gaji.

Berdasarkan tabel 4 diatas dapat disimpulkan bahwa untuk pada variabel ketepatan pemberian obat didapatkan 28 responden $(87,5 \%)$ tepat dalam pemberian obat dan 4 responden $\quad(12,5 \%)$ tidak tepat dalam pemberian obat.
Tabel 3. Kategori kepuasan kerja perawat berdasarkan dimensi kepuasan kerja di RS Baptis Batu

\begin{tabular}{lccccc}
\hline $\begin{array}{c}\text { Di- } \\
\text { mensi } \\
\text { kepua- } \\
\text { san } \\
\text { kerja }\end{array}$ & $\begin{array}{c}\text { Sangat } \\
\text { tidak } \\
\text { puas }\end{array}$ & $\begin{array}{c}\text { Tidak } \\
\text { puas }\end{array}$ & $\begin{array}{c}\text { Cukup } \\
\text { puas }\end{array}$ & puas & $\begin{array}{c}\text { Sangat } \\
\text { puas }\end{array}$ \\
\hline Gaji & $\begin{array}{c}6,87 \\
\%\end{array}$ & $19,37 \%$ & $43,75 \%$ & $30 \%$ & $0 \%$ \\
\hline Promosi & 2,08 & $14,58 \%$ & $61,458 \%$ & $21,87 \%$ & $0 \%$ \\
\hline $\begin{array}{l}\text { Rekan } \\
\text { kerja }\end{array}$ & $0 \%$ & $9,37 \%$ & $27,08 \%$ & $48,95 \%$ & $14,58 \%$ \\
\hline $\begin{array}{l}\text { Penga- } \\
\text { was }\end{array}$ & $0 \%$ & $6,25 \%$ & $48,958 \%$ & $41,66 \%$ & $3,12 \%$ \\
\hline $\begin{array}{l}\text { Peker- } \\
\text { jaan itu } \\
\text { sendiri }\end{array}$ & $1,04 \%$ & $14,58 \%$ & $42,70 \%$ & $39,58 \%$ & $3,12 \%$ \\
\hline
\end{tabular}

Tabel 4. Kategori ketepatan pemberian obat di RS Baptis Batu dapat dilihat

\begin{tabular}{lcc}
\hline Kategori & Frekuensi & $\begin{array}{c}\text { Persentase } \\
(\mathbf{\%})\end{array}$ \\
\hline Tepat & 28 & 87,5 \\
\hline Tidak tepat & 4 & 12,5 \\
\hline
\end{tabular}

Tabel 5. Analisis Hubungan antara kepuasan kerja dengan kinerja perawat dalam ketepatan pemberian obat di Ruang Rawat Inap RS Baptis batu

\begin{tabular}{lccc}
\hline \multirow{2}{*}{ Kepuasan kerja } & \multicolumn{2}{c}{ Ketepatan kerja } & Total \\
\cline { 2 - 3 } & Tidak tepat & Tepat & \\
\hline Tidak puas & 4 & 4 & 0 \\
\hline Cukup puas & 0 & 15 & 15 \\
\hline Puas & 0 & 11 & 11 \\
\hline Sangat puas & 0 & 2 & 2 \\
\hline
\end{tabular}

Dari hasil tabulasi 5 silang diketahui bahwa responden yang memiliki kepuasan dalam hal bekerja akan melakukan pekerjaannya dengan baik hal ini dapat dibuktikan dari hasil dimana 46,875 \%responden yang merasa cukup puas melakukan tepat pemberian obat, $34,375 \%$ responden yang puas juga tepat dalam pemberian obat dan $6,25 \%$ responden yang sangat puas terhadap pekerjaannya juga melakukan ketepatan dalam pemberian obat, sedangkan $12,5 \%$ responden yang tidak puas tidak tepat dalam pemberian obat 
Tabel 6. Hasil uji Lamda hubungan antara kepuasan kerja perawat dengan ketepatan pemberian obat di Ruang Rawat Inap RS Baptis batu

\begin{tabular}{cccc}
\hline Jenis Penelitian & $\mathrm{n}$ & $\mathrm{p}$ & $\alpha$ \\
\hline Lamda & 32 & 0,033 & 0,05 \\
\hline
\end{tabular}

Dari uji Lamda tabel 6 didapatkan probabilitas (sig) sebesar 0,033. Karena nilai probabilitas < 0,05 maka untuk interpretasi hasil Ho ditolak dan $\mathrm{H} 1$ diterima. Maka disimpulkan terdapat hubungan antara kepuasan kerja dengan kinerja perawat dalam ketepatan pemberian obat di ruang rawat inap RS Baptis Batu

\section{PEMBAHASAN}

\section{Kepuasan kerja di ruang rawat inap RS Baptis Batu.}

Dalam penelitian ini $43,75 \%$ responden cukup puas dalam hal system penggajian di RS Baptis Batu. Menurut (Mathis dan Jakson, 2011) dalam Andini ( 2015) apabila gaji yang diterima pegawai dirasakan cukup maka kepuasan kerja pegawai tersebut akan terpenuhi Hal ini juga didukung dengan hasil riset Herzberg menyarankan bahwa kompensasi (gaji) dan kondisi kerja harus memadai untuk menjaga karyawan agar merasa puas. Kepuasan kerja pada gilirannya akan memotivasi karyawan untuk bekerja lebih produktif. Karyawan yang bekerja diperusahaan pada dasarnya mempunyai serangkaian kebutuhan yang harus dipenuhi. Gaji yang diterima setiap bulan dapat digunakan untuk memenuhi kebutuhan primer sehari-hari. Karyawan pada umumnya mengharapkan gaji yang ditetapkan secara adil dan memadai untuk mencukupi kebutuhan setiap bulannya, tercukupinya kebutuhan primer tersebut akan berdampak pada rasa puas dalam bekerja.

Dalam dimensi promosi didapatkan 61,458\% responden menjawab cukup puas. Promosi didapatkan dari prestasi kerja yang dicapai pegawai. Prestasi kerja adalah hasil kerja secara kualitas dan kuantitas yang dicapai seorang pegawai dalam melaksanakan tugasnya sesuai dengan tanggung jawab yang diberikan kepadanya. Sistem promosi yang baik dapat mempengaruhi kepuasan kerja dimana perawat merasa memiliki kesempatan yang sama dalam hal menempati posisi jabatan baru yang lebih tinggi maupun promosi untuk mengikuti studi lanjut. Dalam teori dua faktor pada teori motivasi yang dikemukakan oleh Herzberg dalam Robbins (2015:128), menjelaskan bahwa dengan kesempatan kenaikan pangkat orang akan termotivasi untuk bekerja. Menurut Khamlub (2013) dalam Hartanti (2015) bahwa kesempatan untuk maju atau promosi merupakan faktor yang dapat menyebabkan kepuasan kerja.

Untuk Dimensi rekan kerja didapatkan 48,958 responden merasa puas. Hal ini dapat disimpulkan bahwa kerjasama antar perawat di Rumah Sakit Baptis masuk dalam kategori baik dan .dapat diartikan bahwa perawat telah mampu bekerja secara aktif, tidak malu meminta bantuan dan bertanya kepada rekan sekerja, serta memahami dan melaksanakan tugasnya dengan baik bersama rekan sekerjanya.

Pada dimensi pengawasan didapatkan 48,958 responden menyatakan cukup puas. Dari hasil penelitian yang dilakukan oleh Syahrir dkk (2012) bahwa ada hubungan antara supervisi dengan pelaksanaan asuhan keperawatan. Semakin baik supervisi dapat meningkatkan kualitas kerja perawat. Dalam teori $\mathrm{X}$ dan teori $\mathrm{Y}$ yang dikemukakan oleh McGregor dalam Robbins (2015:128), mengemukakan bahwa pada teori X dalam sebuah organisasi para manajer meyakini bahwa para pekerja pada dasarnya tidak menyukai bekerja sehingga harus diarahkan atau bahkan dipaksa untuk melakukan pekerjaannya. Hal ini searah dengan pendapat Herzberg yang mengatakan bahwa supervisi atau pengawasan merupakan salah faktor yang menyebabkan ketidakpuasan (Trisnawati dkk, 2015) Sedangkan dari segi pekerjaan itu sendiri didapatkan 42,708 responden merasa cukup puas. Hal ini dapat disimpulkan bahwa pekerjaan itu sendiri membawa suasana yang nyaman dan menyenangkan sehingga perawat dapat bekerja dengan baik

\section{Kinerja perawat dalam ketepatan pemberian obat di ruang rawat inap RS Baptis Batu}

Berdasarkan hasil penelitian didapatkan 28 responden menyatakan tepat dalam melakukan perasat pemberian obat dan 4 responden tidak tepat dalam prasat pemberian obat.Hal ini menunjukkan bahwa belum semua perawat melaksanakan prinsip ini secara sempurna. Kurangnya pelaksanaan prinsip 7 benar dalam pemberian obat karena berdasarkan hasil penelitan,perawat cenderung hanya melakukan prinsip 6 benar yang tergolong dalam kategori baik yaitu benar obat, benar dosis, benar klien, benar rute, benar waktu, benar dokumentasi untuk prinsip yang ketujuh jarang dilakukan, Hal ini dapat disimpulkan bahwa pengetahuan perawat masih kurang terkait prinsip 7 benar, perawat hanya cukup mengenal 
prinsip 6 benar dalam pemberian obat.. Pengetahuan diperlukan untuk mendapat informasi misalnya halhal yang menunjang pengambilan tindakan yang tepat sehingga dapat meningkatkan kualitas hidup pasien. Pengetahuan dapat mempengaruhi seseorang dalam pengambilan keputusan dan sehingga nantinya akan memotivasi perawat untuk bersikap dan berperan serta dalam peningkatan kesehatan pasien dalam hal ini pemberian tindakan pengobatan dengan tepat ( Harmiady, 2014)

Ketepatan disini harus dilihat dari 7 benar secara keseluruhan. Apabila satu aspek tidak tepat maka akan membuat 7 benar menjadi tidak tepat lagi.Dan dalam penelitian ini kebanyakan perawat masih melakukan prinsip 6 benarMeskipun apabila dilihat dari masing masing aspek dalam prinsip 7 benar menunjukkan adanya perilaku yang positif dari perawat dalam pemberian obat.

\section{Hubungan antara kepuasan kerja dengan kinerja perawat dalam ketepatan pemberian obat di RS Baptis Batu}

Hasil analisa data menggunakan uji lamda didapatkan hasil bahwa probabilitas ( sig) $=0.033$. Ho ditolak dan $\mathrm{H} 1$ diterima jika nilai $\mathrm{p} \leq \alpha$,dalam penelitian ini $\mathrm{p}=0,033 \leq \alpha=0,05$. Maka hasil analisis statistik didapatkan bahwa ada hubungan antara kepuasan kerja dengan kinerja perawat dalam ketepatan pemberian obat di ruang rawat inap RS Baptis Batu. Dari hasil tersebut maka dapat diasumsikan bahwa perawat dengan kepuasan kerja yang rendah cenderung untuk melaksanakan prinsip 7 benar dalam pemberian obat dengan kategori kurang. Kepuasan kerja merupakan salah satu faktor dari motivasi, timbulnya motivasi dalam diri seorang perawat bisa disebabkan oleh adanya rasa tanggung jawab yang timbul dari diri seorang perawat. Jika seseorang memiliki rasa tanggung jawab yang tinggi terhadap pasien maka tentunya perawat akan berusaha semaksimal mungkin untuk melakukan tindakan yang cepat, tepat dan terarah untuk mengatasi masalah pasien termasuk ketapatan dalam pemberian obat.(Nursalam 2010). Aspek lain yang bisa menimbulkan kepuasan kerja pada seorang perawat adalah adanya rangsangan yang diterima dari Rumah Sakit. Rangsangan tersebut bisa dalam bentuk penghargaan yang diterima, insentif kerja serta pujian. Hasil penelitian Juliani yang mengkaji motivasi intrinsik terhadap kinerja perawat dirumah sakit $\mathrm{P}$ medan menunjukkan bahwa ada pengaruh yang signifikan antara motivasi intrinsik berdasarkan tanggung jawab, peluang untuk maju, dan kepuasan kerja terhadap kinerja perawat di rumah sakit.

\section{KESIMPULAN}

Berdasarkan hasil penelitian dan pembahasan tentang hubungan kepuasan kerja dengan kinerja perawat dalam pelaksanaan prinsip 7 benar dalam pemberian obat di ruang rawat inap RS Baptis Batu , dapat disimpulkan kepuasan kerja perawat di ruang rawat inap RS Baptis Batu termasuk dalam kategori cukup Pelaksanaan prinsip 7 benar dalam pemberian obat di ruang rawat inap RS Baptis Batu termasuk dalam kategori baik

Terdapat hubungan antara kepuasan kerja dengan pelaksanaan prinsip 7 benar dalam pemberian obat di ruang rawat inap RS Baptis Batu

\section{DAFTAR PUSTAKA}

Andini. (2015). Hubungan Antara Aspek Penghargaan dengan Kepuasan Kerja Perawat Di Ruang Rawat Inap RSUD Muntilan. Program Studi Ilmu Keperawatan Sekolah Tinggi Ilmu Kesehatan Aisyiyah Yogyakarta

Asmadi. (2008). Konsep DasarKeperawatan, Jakarta : EGC

Aster Nila, Marta Halim. (2013). Dasar - Dasar Farmakologi 2 kelas x Semester 2.Direktorat Pembinaan SMK

Christofer dan Kesumawati, Maya Ida. (2015). Pengaruh Teori Dua Faktor Frederick Herzberg (Hygiene and Motivator Factor) Terhadap Kepuasan Kerja Karyawan di Perusahaan Ritel Infinite Apple Premium Reseller Surabaya. Jurnal Media Mahardika Vol. 13, No. 3.

DepKes RI . (2008). Tanggung Jawab Apoteker terhadap Keselamatan Pasien (Patient Safety). Jakarta

Depkes RI .2011. Modul penggunaan obat rasional Direktorat Farmasi Komunitas dan Klinik Ditjen Bina Kefarmasian dan Alat Kesehatan Direktorat Bina Penggunaaan Obat Rasional DepKes. (2008). Modul I Materi Pelatihan Peningkatan Pengetahuan dan Keterampilan Memilih Obat bagi Tenaga Kesehatan..

Dugguh, Stephen I. Ph. D, Ayaga, And Dennis, Ph. D. (2014). Job Satisfaction Theories : Traceability to Employee Performance in Organizations. IOSR Journal of Business and Management . Volume 16 issue 5 ver. I. Department of Business Management Benue State University, Makurdi. 
Cetakan kelima. Jakarta. Bumi Aksara

Fiky Rofiqoh. (2015) Hand Out Keterampilan Dasar

Kebidanan.Akbid Al-ishlah Cilegon

Hasibuan MSP.(2005). Manajemen Sumber Daya Manusia. 